\title{
A soft-tissue vertical line to research the profile harmony
}

\author{
Fabio Ciuffolo* \\ Viale Matrino 124, 65013, Città Sant'Angelo (PE), Italy
}

\section{Introduction}

The anterior-posterior position of upper incisor is a determinant of the ideal soft-tissue profile [1]. For this reason, from the beginning of our specialty, "the profile with perfect harmony" was researched [2] and different analysis have been described for this purpose [1-5]. Since many variables have been used to analyse the ideal soft tissue profile, the aim of this clinical paper is to describe and propose an easy and quick analysis to establish the anterior-posterior position of upper incisor in relation to the soft-tissue profile, by using two lines and two soft-tissue landmarks.

\section{Harmony Vertical Line (HVL) analysis (Figure-1).}

1. Take the ceph with the head in natural head position and lip at rest.

2. Mark Porion and Orbital in order to draw Frankfort Horizontal (FH).

3. Mark the alar base (the most posterior point of the alar nose).

4. Draw the HVL on the alar base landmark, perpendicular to FH.

5. The labial surface of upper incisor (UI) and the soft-tissue Gnathion (STG) should be on the HVL.

The HVL analysis were performed by using Dolphin Imaging software, Chatsworth, CA, USA. www.dolphinimaging.com

\section{Clinical consideration}

This analysis may help the clinician in establishing the anteriorposterior position of both upper incisor and the soft-tissue Gnathion in relation to the HVL. This relation may be easily and quickly found and also transported to the clinical picture of smiling profile, although it is taken in a dynamic condition (Case-2, Case-3 and Case-5). However, the orthodontists should be aware that several further variables may influence the profile harmony, such as the vertical skeletal pattern of the face, the soft tissue thickness, the lip length, ethnicity [3,4,6,7], patient's perception [8] which must be also considered when the "the profile of perfect harmony" is researched. The harmonization of the profile in the following case series with different type of malocclusion is shown by using the HVL analysis (Case-1: lower incisor (LI) protrusion, STG retrusion; Case-2: UI retrusion; Case-3: LI and STG restrusion; Case4: UI protrusion, LI and STG retrusion; Case-5: UI and LI protrusion, STG retrusion; Case-6: UI and LI retrusion).

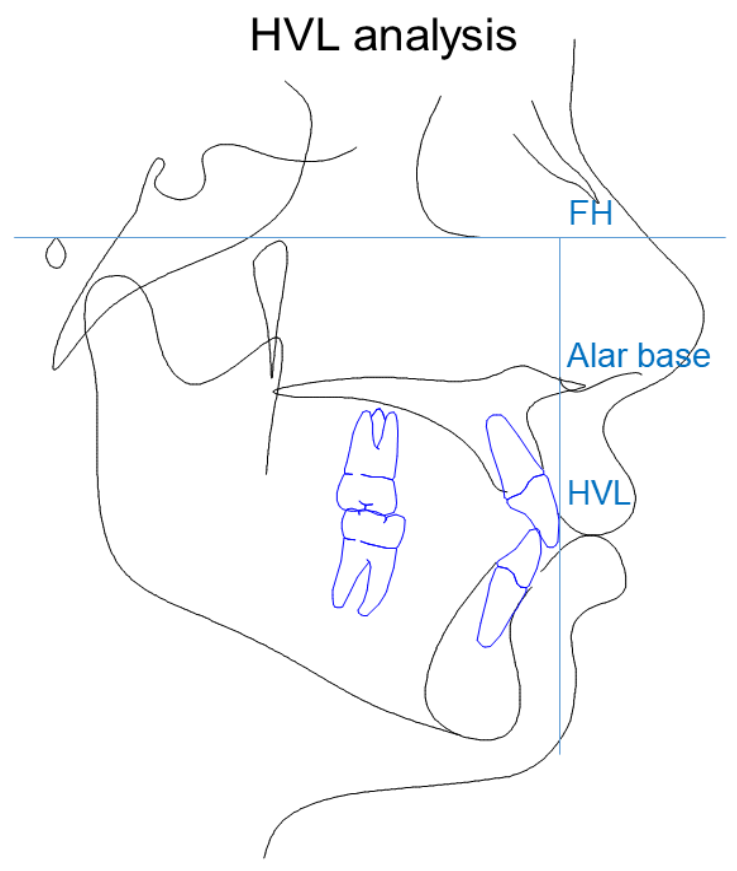

${ }^{\star}$ Correspondence to: Fabio Ciuffolo, DDS, PhD, Viale Matrino 124, 65013, Città Sant'Angelo (PE), Italy, E-mail: fabio@studiociuffoloferritto.it

Received: August 01, 2020; Accepted: August 17, 2020 Published: August 21, 2020 

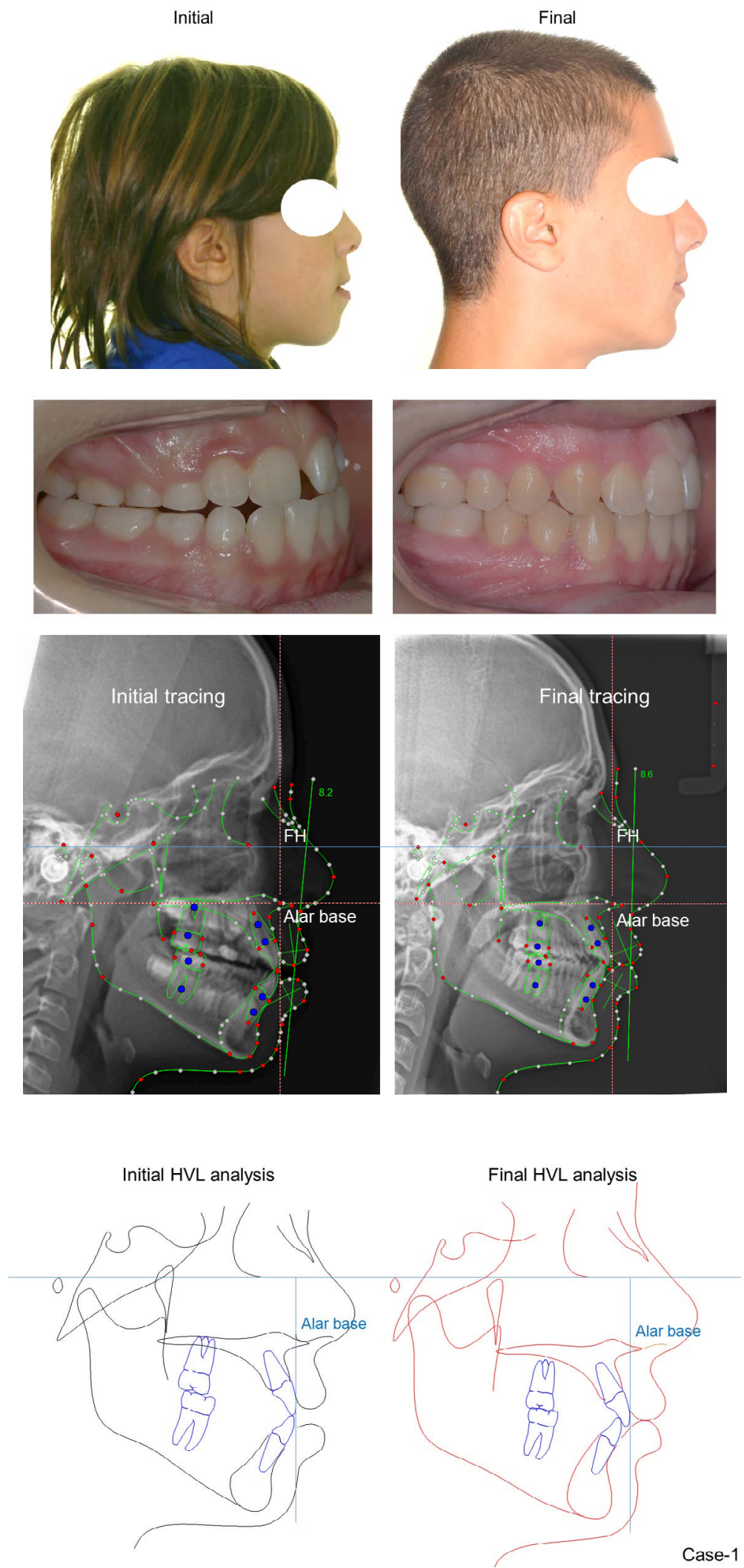

Case 1. The initial HVL analysis showed a LI protrusion and a STG retrusion. The final HVL analysis showed the harmonization of the profile associated with a better relation of both incisors and the STG to the HVL 

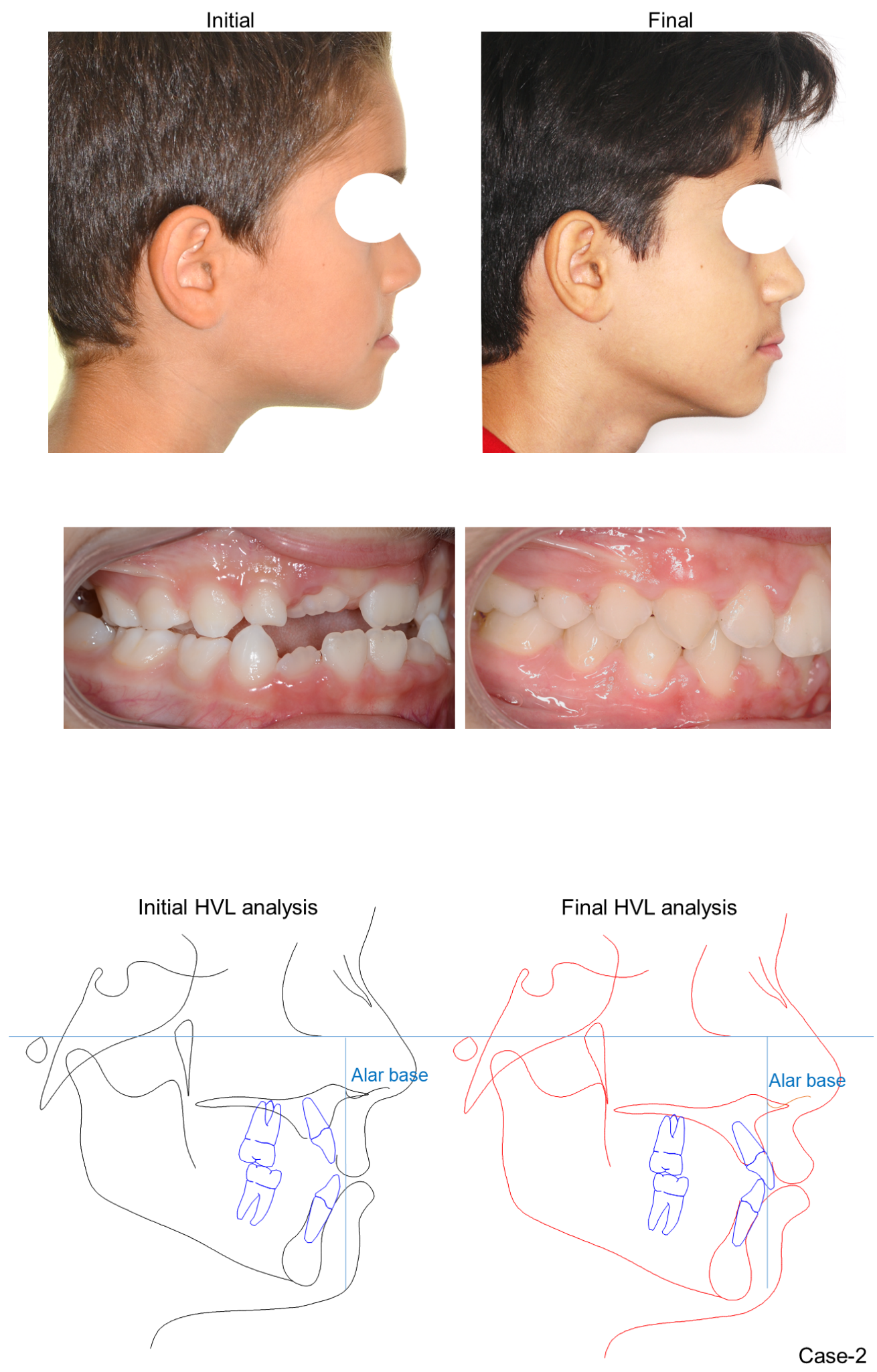

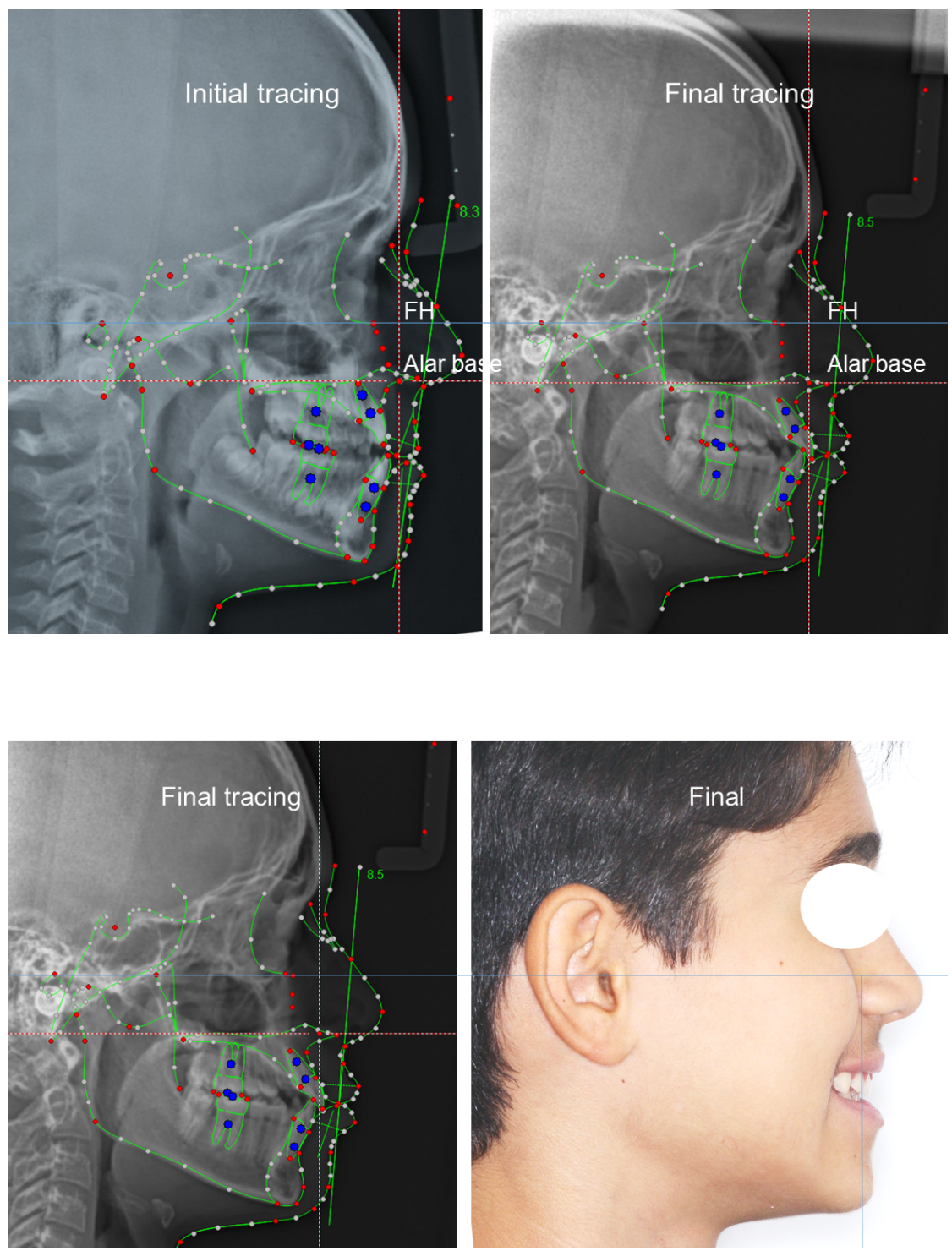

Case 2. The initial HVL analysis showed an UI retrusion. The final HVL analysis showed the harmonization of the profile associated with a better relation of UI to the HVL
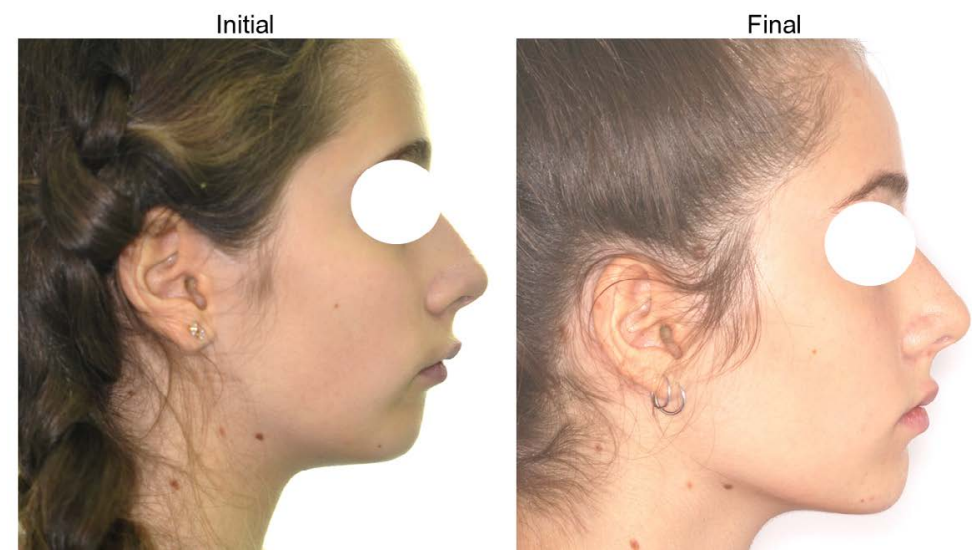

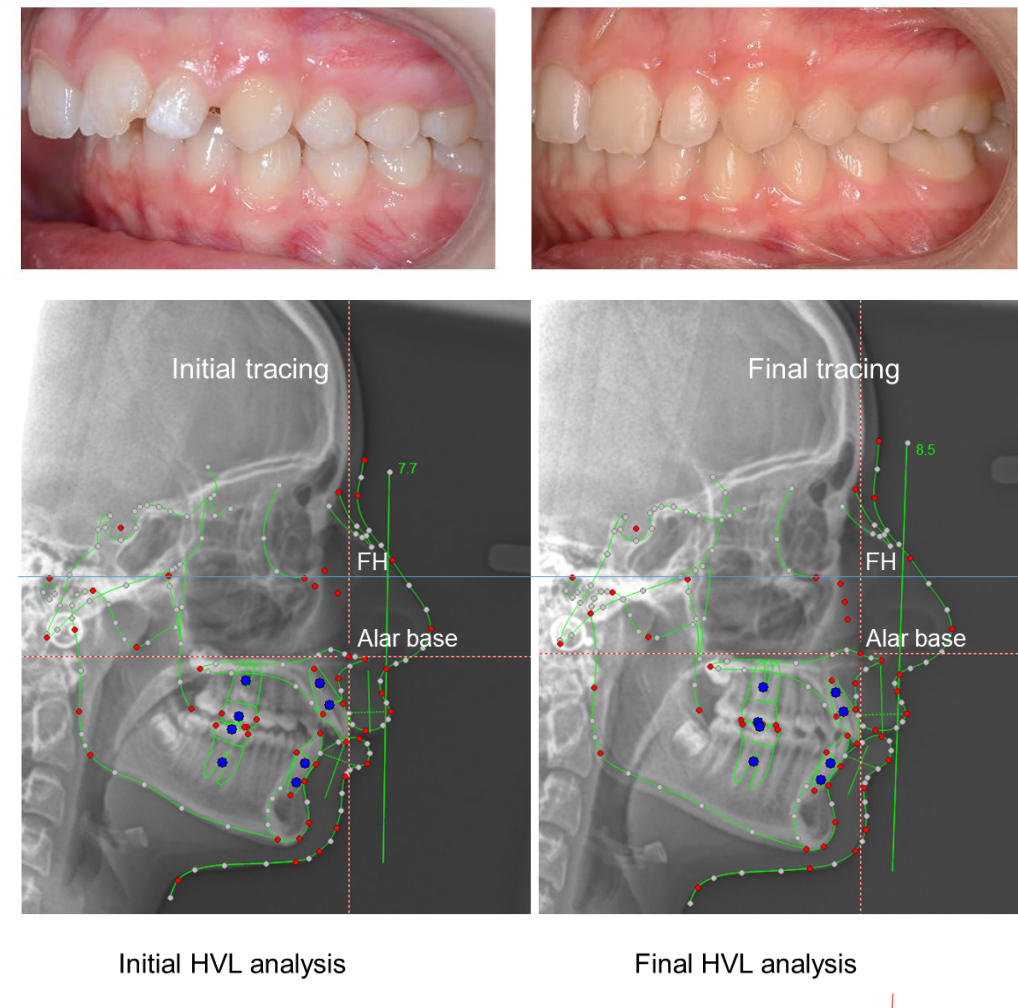

Final HVL analysis
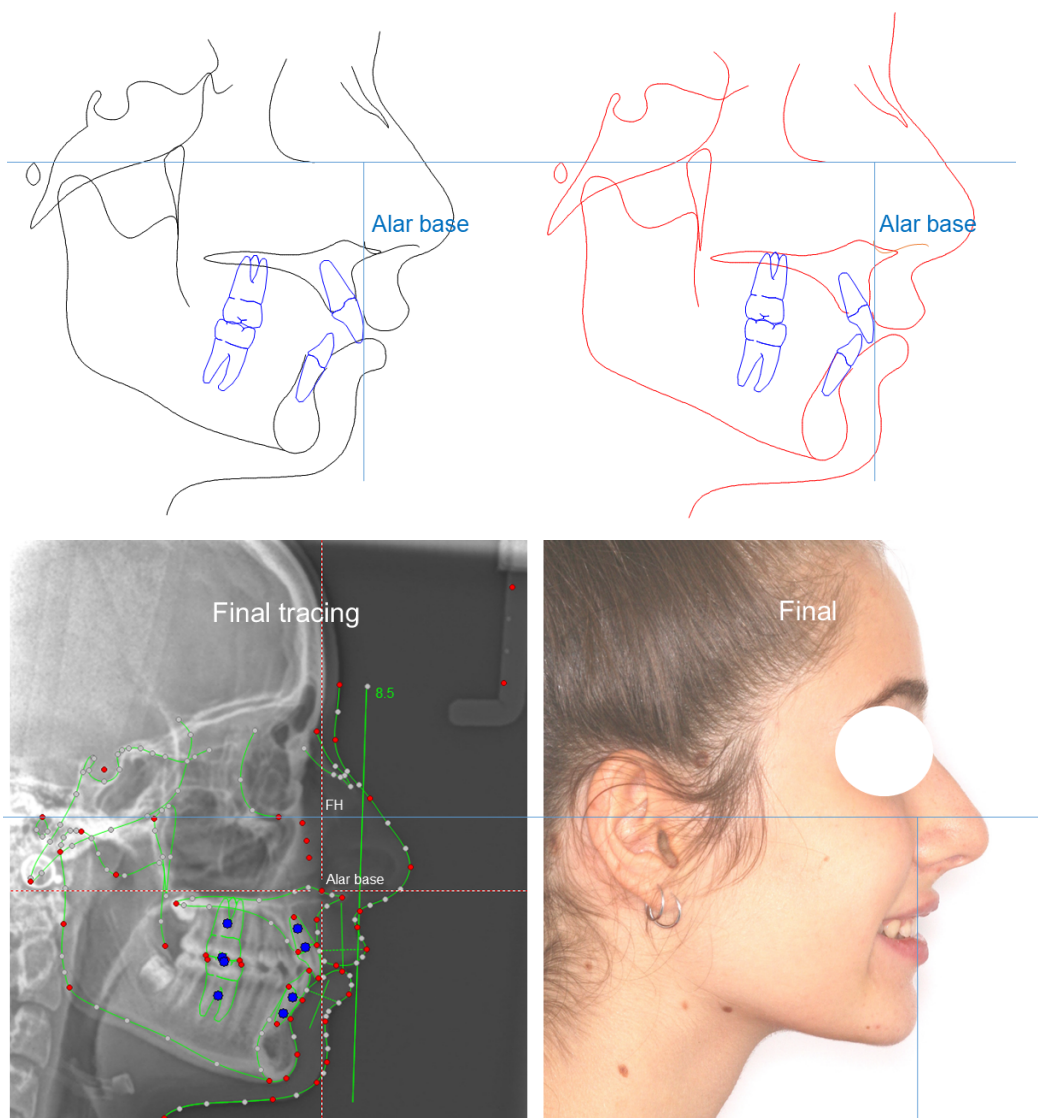

Case 3. The initial HVL analysis showed a retrusion of both LI and STG. The final HVL analysis showed the harmonization of the profile associated with a better relation of both LI and STG to the HVL 

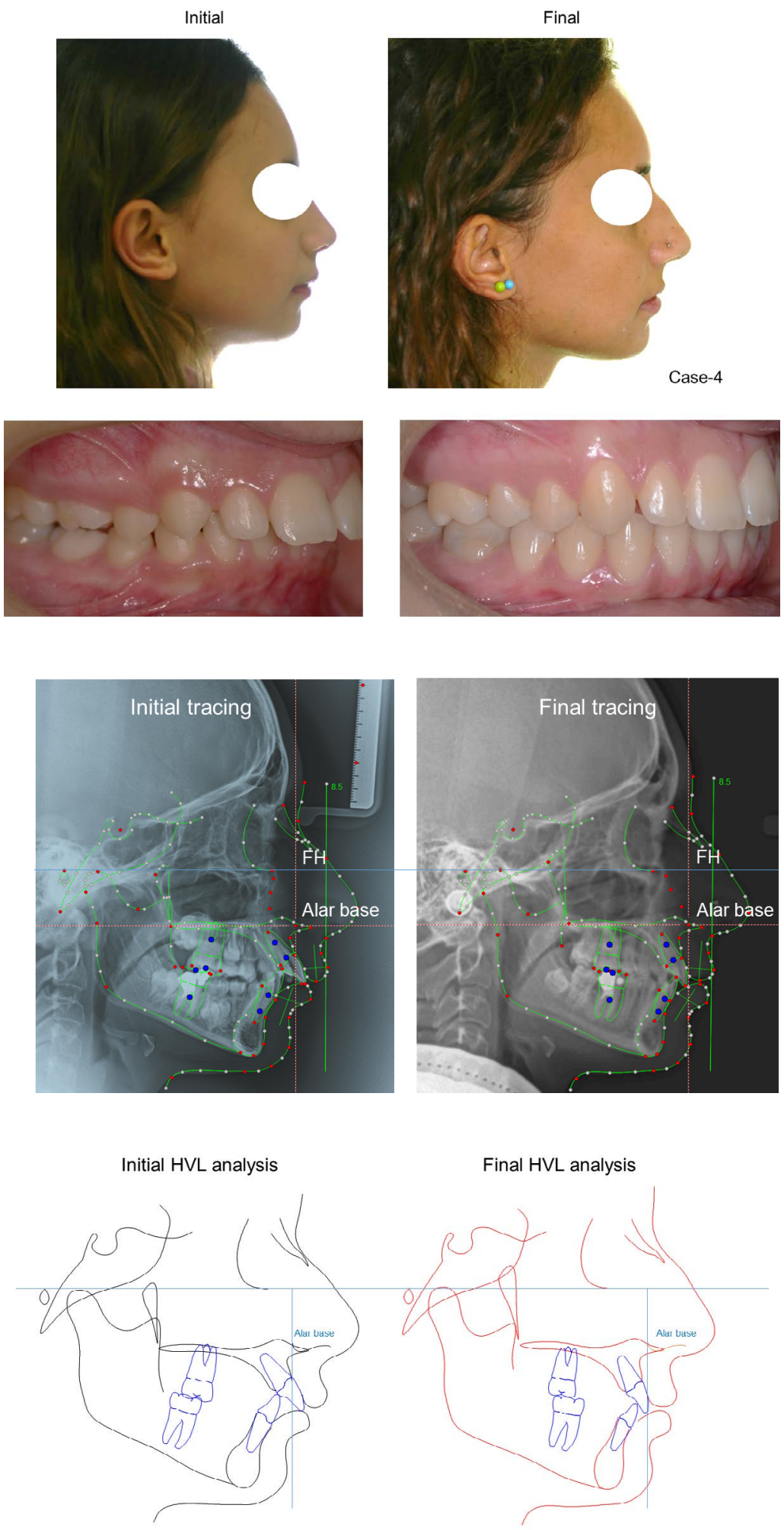

Final HVL analysis

Case 4. The initial HVL analysis showed an UI protrusion and a STG retrusion. The final HVL analysis showed the harmonization of the profile associated with a better relation of both UI and STG to the HVL 

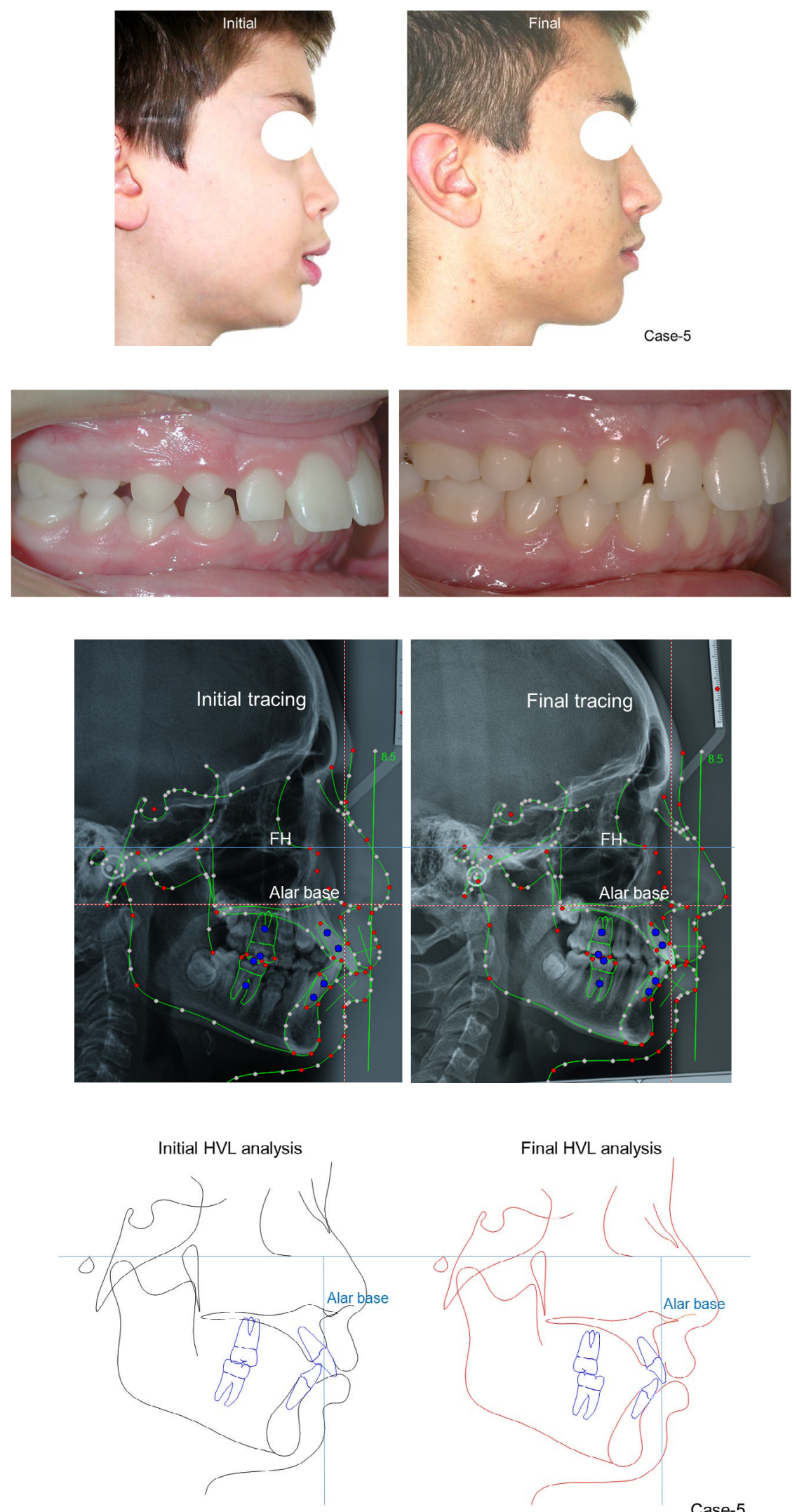

Final HVL analysis

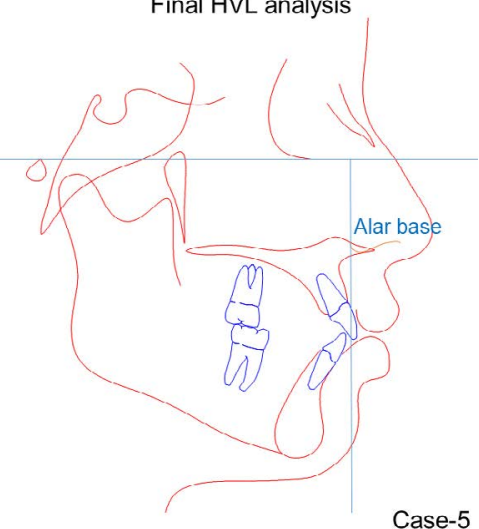



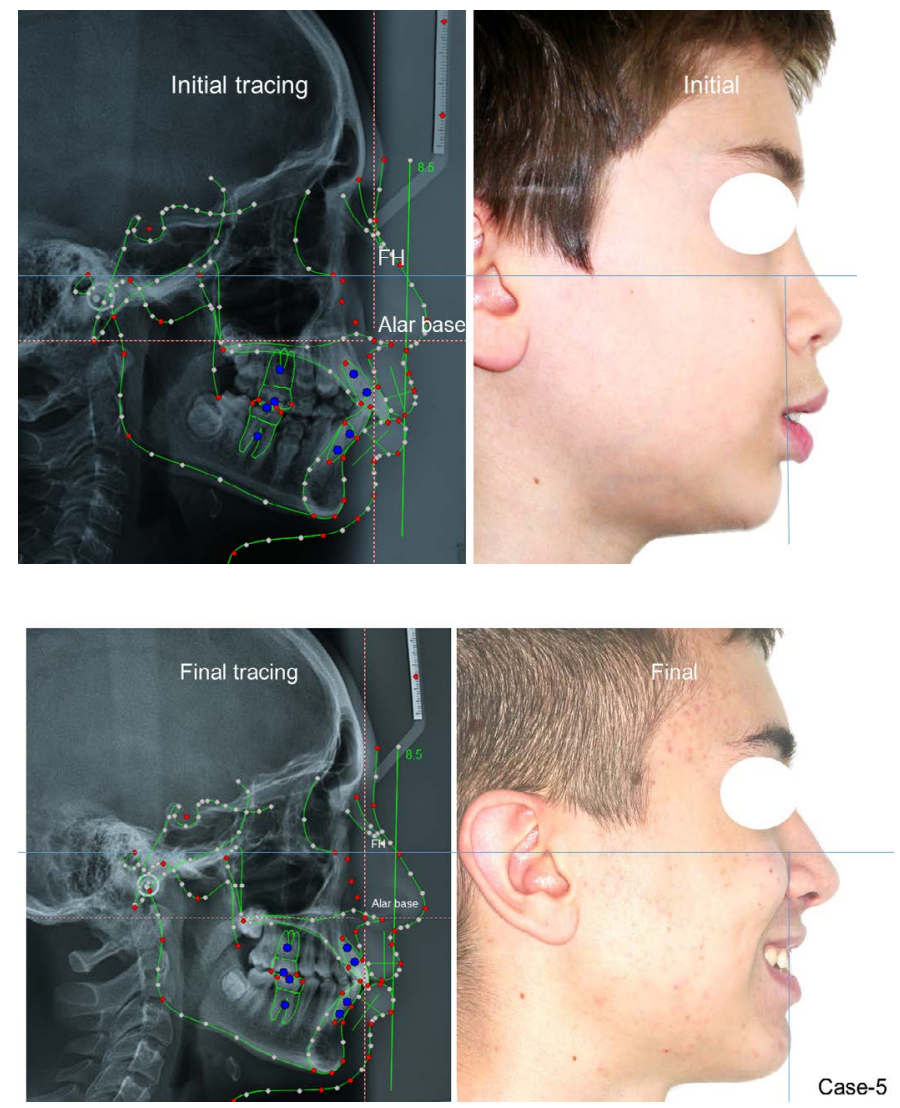

Case 5. The initial HVL analysis showed a protrusion of both UI and LI, a retrusion of STG. The final HVL analysis showed the harmonization of the profile associated with a better relation of incisors and STG to the HVL
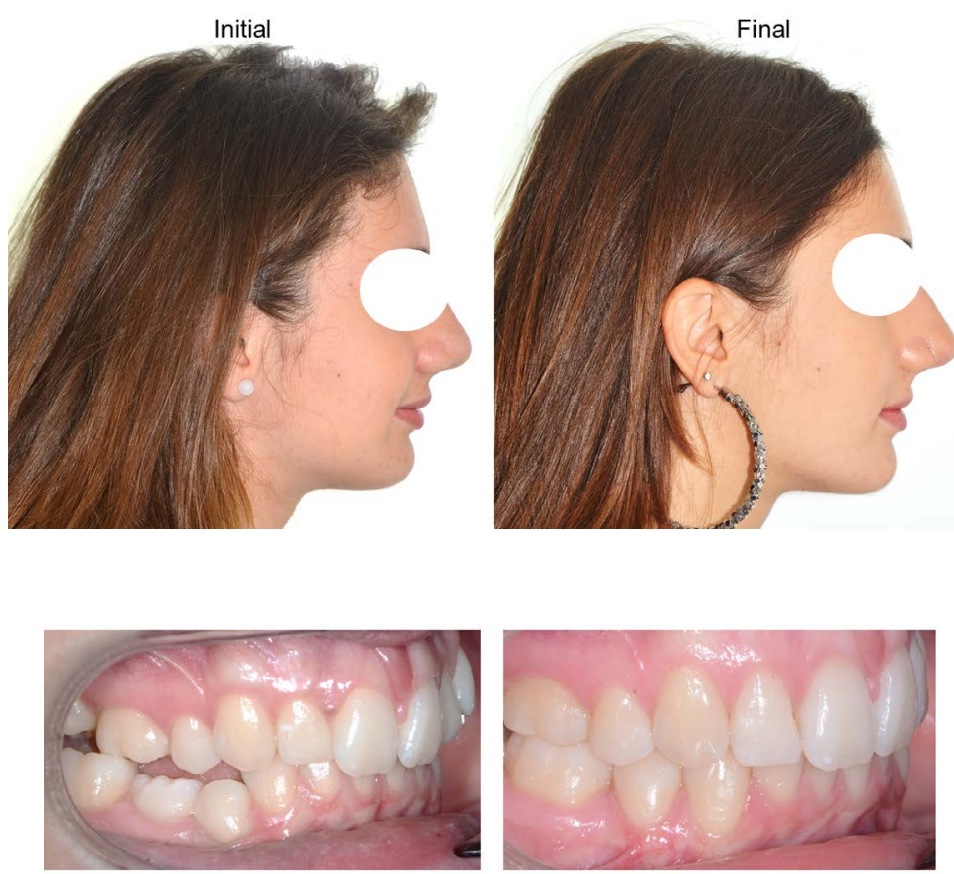

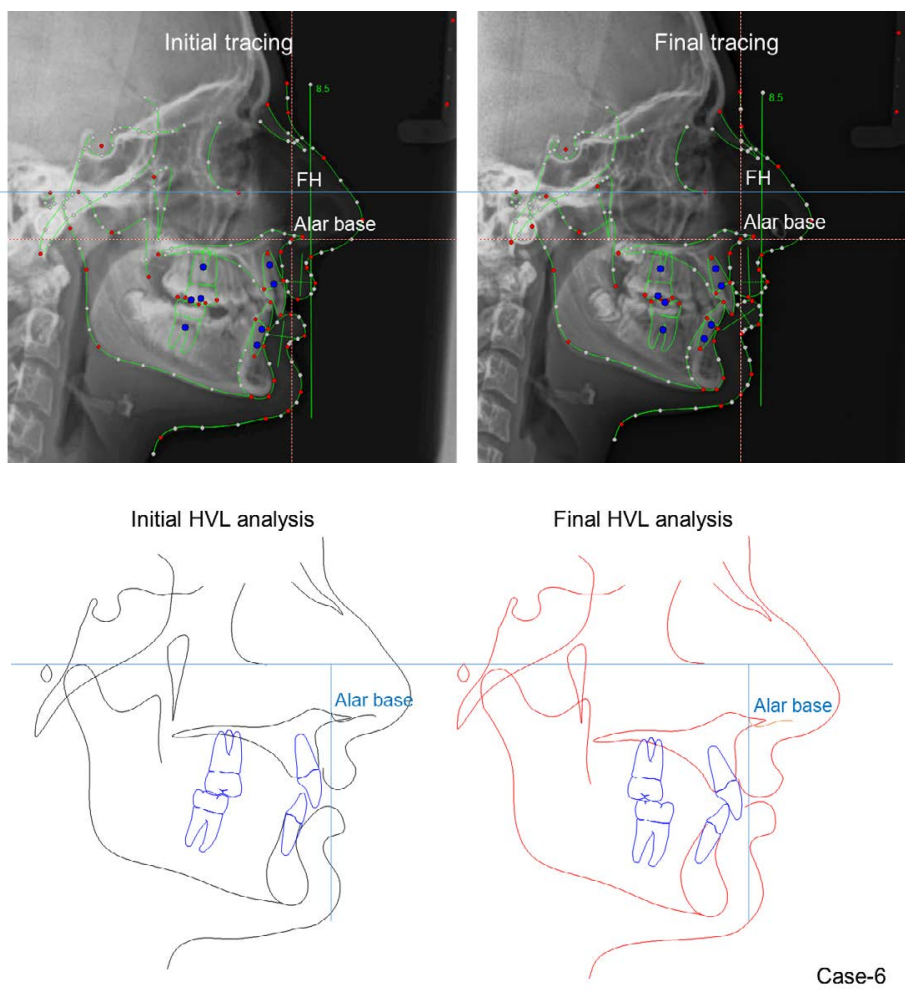

Case 6. The initial HVL analysis showed a retrusion of both UI and LI. The final HVL analysis showed approximately the same harmony with the same relation of incisors and STG to the HVL, despite the correction of malocclusion occurred with lower molar protraction

\section{Disclosure}

Acknowledgement to Dr Antonio Guiducci; MD, specialist in orthodontics.

\section{References}

1. Webb MA, Cordray FE, Rossouw PE (2016) Upper incisor position as a determinant of the ideal soft-tissue profile. J Clin Orthod 11: 651-662. [Crossref]

2. Angle EH (1900) The treatment of malocclusion of the teeth and fractures of the maxillae. 6th ed. Philadelphia: S.S. White: 15-23.

3. Ackerman JL, Proffit WR (1997) Soft tissue limitations in orthodontics: treatment planning guidelines. Angle Orthod 67: 327-336.
4. Arnett GW, Jelic JS, Kim J, Cummings DR, Beress A, et al. (1999) Soft tissue cephalometric analysis: Diagnosis and treatment planning of dentofacial deformity. $A m$ J Orthod Dentofacial Orthop 116: 239-53. [Crossref]

5. Andrews WA (2008) AP Relationship of the maxillary central incisors to the forehead in adult white females. Angle Orthod 78: 662-9. [Crossref]

6. Carruitero MJ, Ambrosio-Vallejos XM, Flores-Mir C (2019) Glabellar vertical line as a reference goal for anteroposterior maxillary position. Dental Press J Orthod 24: 1-5.

7. Manevska I, Pavlic A, Katic V, Trinajstic Zrinski M, Drevensek M et al. (2018) Satisfaction with facial profile aesthetics: are norms overrated J Oral Maxillofac Surg 47: 72-78. [Crossref]

8. Eslami N, Omidkhoda M, Shafaee H, Mozhdehifard M (2016) Comparison of esthetics perception and satisfaction of facial profile among male adolescents and adults with different profiles. J Orthod Sci 5: 47-51. [Crossref]

Copyright: (C2020 Ciuffolo F. This is an open-access article distributed under the terms of the Creative Commons Attribution License, which permits unrestricted use, distribution, and reproduction in any medium, provided the original author and source are credited. 